\title{
Excessive Neutrophils and Neutrophil Extracellular Traps Contribute to Acute Lung Injury of Influenza Pneumonitis
}

\author{
Teluguakula Narasaraju, ${ }^{*}$ Edwin Yang, ${ }^{*}$ \\ Ramar Perumal Samy, ${ }^{*}$ Huey Hian Ng, ${ }^{*}$ \\ Wee Peng Poh, ${ }^{*}$ Audrey-Ann Liew, ${ }^{*}$ \\ Meng Chee Phoon, ${ }^{*}$ Nico van Rooijen, ${ }^{\dagger}$ and \\ Vincent T. Chow* \\ From the Infectious Diseases Program,* Department of \\ Microbiology, Yong Loo Lin School of Medicine, National \\ University of Singapore, Kent Ridge, Singapore; and the \\ Department of Molecular Cell Biology, ${ }^{\dagger}$ Faculty of Medicine, \\ Vrije University of Amsterdam, Amsterdam, the Netherlands
}

Complications of acute respiratory distress syndrome (ARDS) are common among critically ill patients infected with highly pathogenic influenza viruses. Macrophages and neutrophils constitute the majority of cells recruited into infected lungs, and are associated with immunopathology in influenza pneumonia. We examined pathological manifestations in models of macrophage- or neutrophil-depleted mice challenged with sublethal doses of influenza A virus H1N1 strain PR8. Infected mice depleted of macrophages displayed excessive neutrophilic infiltration, alveolar damage, and increased viral load, later progressing into ARDS-like pathological signs with diffuse alveolar damage, pulmonary edema, hemorrhage, and hypoxemia. In contrast, neutrophil-depleted animals showed mild pathology in lungs. The brochoalveolar lavage fluid of infected macrophage-depleted mice exhibited elevated protein content, T1- $\alpha$, thrombomodulin, matrix metalloproteinase-9, and myeloperoxidase activities indicating augmented alveolarcapillary damage, compared to neutrophil-depleted animals. We provide evidence for the formation of neutrophil extracellular traps (NETs), entangled with alveoli in areas of tissue injury, suggesting their potential link with lung damage. When co-incubated with infected alveolar epithelial cells in vitro, neutrophils from infected lungs strongly induced NETs generation, and augmented endothelial damage. NETs induction was abrogated by anti-myeloperoxidase antibody and an inhibitor of superoxide dismutase, thus implying that NETs generation is induced by redox enzymes in influenza pneumonia. These findings support the pathogenic effects of excessive neutrophils in acute lung injury of influenza pneumonia by instigating alveolar-capillary damage. (Am J Pathol 2011, 179:199-210; DOI: 10.1016/j.ajpath.2011.03.013)

Histopathological analyses of lungs of patients who succumb to highly pathogenic influenza pneumonia show complications of acute respiratory distress syndrome (ARDS), a severe form of acute lung injury (ALI), with massive pulmonary edema, diffuse alveolar damage (DAD) and respiratory failure. ${ }^{1-5}$ Lower respiratory tract manifestations are observed in patients at the early stages of severe influenza virus infection, with radiographic evidence of diffuse, multifocal, patchy interstitial infiltrates with fulminant progression into ARDS. ${ }^{1,4}$ Likewise, most of the patients who died of severe acute respiratory syndrome (SARS) during the outbreak in 2003 developed ARDS. ${ }^{6}$ Clinical and pathological signs of infective ARDS were also corroborated in macaque and other animal models of influenza virus infections. ${ }^{7-9} \mathrm{Al}-$ though ARDS is a prevailing complication in influenzaassociated deaths, the etiology for progression into ARDS is poorly understood.

Excessive recruitment and activation of neutrophils have been implicated in ALI in several disease conditions. ${ }^{10-16}$ The role of neutrophils in influenza virus pathogenesis has been debated. Although reports implicate the possible involvement of neutrophils in ARDS complications in mice challenged with influenza virus, ${ }^{8,9}$ there is a paucity of evidence to reinforce their role. Neutrophil-dominant infiltrations within the affected areas of lungs with complications

Supported by the National Medical Research Council, Singapore, and the Microbiology Vaccine Initiative, National University of Singapore.

Accepted for publication March 3, 2011.

Address reprint requests to Vincent Chow, M.D., Ph.D., Infectious Diseases Program, Department of Microbiology, Yong Loo Lin School of Medicine, National University Health System, National University of Singapore, 5 Science Drive 2, Kent Ridge 117597, Singapore. E-mail: micctk@nus.edu.sg. 
of DAD, intra-alveolar-associated hemorrhage have been documented in human cases ${ }^{17-20}$ as well as in animal models $^{8,9,21-23}$ of severe influenza. Mice lacking interleukin 17 receptor A (IL-17RA), or mice treated with antibody against macrophage inflammatory protein-2 (MIP-2; a potent regulator of neutrophil recruitment) are protected from lethal influenza A/PR/8/34 H1N1 challenge. ${ }^{24,25}$ Congruent with the role of MIP-2 in ALI, increased neutrophil recruitment was observed in mice challenged with reconstituted 1918 H1N1 virus. ${ }^{21}$ Mice lacking IL-1 and tumor necrosis factor- $\alpha$ (TNF- $\alpha$ ) exhibit delay in onset of death following lethal influenza infection. ${ }^{26}$ On the other hand, neutrophils have ameliorative effects, given that neutrophil depletion enhances lethality in influenzainfected mice. ${ }^{27,28}$ Macrophages and neutrophils constitute the majority of infiltrated cells into the lungs in highly pathogenic influenza virus infections. Here, we explored the effects of depleting macrophages or neutrophils on the pathogenesis of influenza pneumonitis.

Neutrophils are terminally differentiated cells with primary roles in innate immunity through phagocytosis of microbial pathogens, production of reactive oxygen intermediates and toxic enzymes such as elastase, or by formation of neutrophil extracellular traps, or NETs. ${ }^{11,12,29-31}$ NETs formation is a new paradigm of cell death mechanisms, such that in response to infection or other stimuli, neutrophils emit their DNA fibers, which carry nuclear and cytoplasmic proteins, including histones, elastase, myeloperoxidase (MPO), pentraxin, matrix metalloproteinase-9 (MMP-9), and bactericidal permeability-increasing protein (BPI). Although NETs aid in trapping bacteria and other pathogens, their prolonged presence may lead to tissue damage. ${ }^{32-34}$ DNA fibers in NETs attach to the capillary endothelium, and are embroiled in vascular damage in sepsis and small vessel vasculitis. ${ }^{30,35}$ Reactive oxygen intermediates, NADPH oxidase, or anti-proteinase 3 (PR-3) are known to mediate NETs induction. ${ }^{36,37}$ Neutrophils activated by IL-8 or phorbol myristate acetate (PMA) also form NETs. ${ }^{29}$ Bacteria such as Streptococcus pneumoniae and Staphylococcus aureus survive even in the presence of NETs by producing endonucleases (which digest NETs) or catalase (which metabolizes hydrogen peroxide). ${ }^{36,38}$ NETs formation in viral infections is virtually unknown, except for a recent study that demonstrated modulation of NETs formation in feline leukemia virus infections. ${ }^{39}$

Here, we exploited macrophage- or neutrophil-depleted animals to unravel the association of these cells with ALI in influenza pneumonia. Our results show that macrophage-depleted animals suffered complications of ARDS when challenged with sublethal influenza virus infection, in contrast to neutrophil-depleted animals that developed only mild lung injury. For the first time, we demonstrated the induction of NETs during influenza virus infection both in vitro and in vivo. NETs were lodged within the areas of alveolar destruction, thus suggesting their putative role in lung damage. Additional in vitro studies revealed the participation of NETs in endothelial damage, and that the regulation of NETs formation was dependent on activation of redox enzymes.

\section{Materials and Methods}

\section{Virus, Animals, and Ethics Approval}

Influenza A virus A/Puerto Rico/8/34 H1N1 (PR8) obtained from the American Type Culture Collection (Manassas, VA) was propagated in embryonated eggs at $37^{\circ} \mathrm{C}$ for 72 hours, and the allantoic fluid was harvested. Virus titers were determined by the plaque assay via infection of Madin-Darby canine kidney (MDCK) cells. Female 4- to 6-week-old BALB/c mice were housed in microisolator cages in an animal BSL-2 laboratory facility. All animal experiments were approved by the Institutional Animal Care and Use Committee, National University of Singapore (protocol number 035/07), and were performed in strict accordance with the recommendations.

\section{Macrophage and Neutrophil Depletion and Infection}

Macrophage depletion in lungs was achieved using the liposome-mediated macrophage suicide technique. Liposome-encapsulated dichloromethylene diphosphonate (clodronate-liposome, L-Cl2MDP) is taken up by macrophages by phagocytosis and induces apoptosis. ${ }^{40}$ Clodronate was a gift from Roche Diagnostics (Mannheim, Germany), and was encapsulated in liposomes as described earlier. ${ }^{41} \mathrm{~L}-\mathrm{Cl}$ 2MDP was administered intranasally (50 $\mu \mathrm{L}$ per dose per mouse) at days -4 and -1 before virus challenge. For depletion of neutrophils, purified rat anti-Ly6G monoclonal antibody $1 \mathrm{~A} 8^{42}$ was administered intraperitoneally (at a dose of $200 \mu \mathrm{g}$ per mouse) 1 day before infection and every 48 hours thereafter. Animals were divided into five groups, ie, uninfected allantoic fluidinoculated control (Con), clodronate-liposome-treated (CL), infected (INF), clodronate-liposome-treated and infected $(C L-I)$, and 1A8-treated and infected (1A8-I). Two separate sets of mice (each consisting of five animals) were tested, one set for bronchoalveolar lavage fluid (BALF) and virus titer analyses, and the other for histopathology. The group of animals treated with $1 \mathrm{~A} 8$ alone did not show any pathological changes in their lungs, and were thus excluded from further study. Within the infected groups, each animal was challenged with a sublethal dose of 100 plaque-forming units (PFU) of PR8 virus through intranasal inoculation. Animals were monitored daily for clinical signs of infection and body weight loss. In separate experiments involving lethal virus challenge, each animal was infected with 500 PFU of virus.

\section{Lung Histopathology and BALF Analysis}

The lungs of one group of animals were harvested for BALF and lung homogenate, whereas lungs for histopathology were obtained from a separate group of mice. After BALF collection, the corresponding lungs were not used for any further experiments. For histopathological 
analyses, lungs were fixed in neutral-buffered formalin and embedded in paraffin. The severity of ALI was evaluated by a semiquantitative histology score in a blinded manner as described previously. ${ }^{43}$ Animals were anesthetized with intraperitoneal injections of ketamine $(75 \mathrm{mg} / \mathrm{kg})$ and medetomidine $(1 \mathrm{mg} / \mathrm{kg})$, and bronchoalveolar lavage was performed immediately after sacrifice as described previously. ${ }^{43}$ The left lung was tied with nylon thread, and the right lung was lavaged twice with a total volume of $800 \mu \mathrm{L}$ of sterile phosphate-buffered saline (PBS) inserted through an endotracheal tube. The recovery of BALF was more than $90 \%$ for all animals. For differential cell counts, the cells were processed onto microscopic slides using a CytoFuge 2 cytocentrifuge (StatSpin, Westwood, MA), and subjected to modified Giemsa staining. Cells (500 per animal) were counted at a magnification of $\times 400$. The supernatants were stored at $-70^{\circ} \mathrm{C}$ for measurement of protein content and enzyme activities. Virus titers were determined, and BALF protein content was measured by the DC Protein Assay Kit (Bio-Rad, Hercules, CA). To evaluate secondary bacterial infection, $40 \mu \mathrm{L}$ of each BALF sample was plated onto nutrient agar and sheep blood agar, and incubated at $37^{\circ} \mathrm{C}$ for 3 days.

\section{Measurement of MPO Enzymatic Activity}

MPO activity in the BALF and lung homogenate was assayed as described previously. ${ }^{43}$ The MPO activity was calculated using the formula: units/milliliter $=\Delta \mathrm{OD} /$ minute $\times 45.1$, expressed as $U / \mathrm{mg}$ protein, where $\Delta O D$ is the change in optical density of the sample. One unit of the enzyme is defined as the amount that consumes 1 $\mu$ mol of $\mathrm{H}_{2} \mathrm{O}_{2}$ per minute.

\section{Western Blot Analysis}

Western blot analyses were performed as described previously. ${ }^{43}$ Briefly, equal volumes of BALF samples were solubilized in SDS sample buffer $[62.5 \mathrm{mmol} / \mathrm{L}$ Tris- $\mathrm{HCl}$ ( $\mathrm{pH}$ 6.8), 5\% 2-mercaptoethanol, 2\% SDS, $10 \%$ glycerol, $0.01 \%$ bromophenol blue], separated by SDS-PAGE (12\%), and then transferred onto a nitrocellulose membrane at $100 \mathrm{~mA}$ for 2 hours, followed by blocking for 1 hour with $5 \%$ milk in $100 \mathrm{mmol} / \mathrm{L}$ Trisbuffered saline containing $0.1 \%$ Tween 20 . Each membrane was incubated at $4^{\circ} \mathrm{C}$ overnight with 1:1000 dilutions of antibodies against thrombomodulin (an integral membrane protein of endothelial cells), T1- $\alpha$ (a plasma membrane protein expressed on alveolar type I pneumocytes), or MMP-9 (a major protein in neutrophil tertiary granules) (Santa Cruz Biotechnology, Santa Cruz, CA). Each membrane was then washed thrice (5 minutes each) in $100 \mathrm{mmol} / \mathrm{L}$ Tris-buffered saline containing $0.1 \%$ Tween 20 , and incubated for 1 hour with 1:5000 dilutions of horseradish peroxidaseconjugated secondary IgG (Santa Cruz Biotechnology). After washing thrice (5 minutes each), each blot was developed with enhanced chemiluminescence reagents and exposed to X-ray film to visualize the pro- tein bands. Densitometric analyses were performed for all protein bands using a Bio-Rad densitometer.

\section{Arterial Blood Gas Analyses}

Four mice from each group were anesthetized at 10 days postinfection (dpi). Each arterial blood sample $(0.3 \mathrm{~mL})$ was withdrawn into a heparinized syringe by percutaneous left ventricular sampling of lightly anesthetized mice spontaneously breathing room air. ${ }^{8}$ Blood gas analysis was immediately performed using a CG8+ cartridge (i-STAT; Abbott Point of Care, Princeton, NJ).

\section{Detection of Neutrophil Extracellular Traps by IHC}

Immunohistochemical analyses on formalin-fixed lung sections were performed as described previously. ${ }^{43}$ Briefly, lung sections were deparaffinized in xylene, permeabilized with $0.5 \%$ Triton X-100 in PBS for 20 minutes, and blocked with $5 \%$ milk in PBS for 30 minutes. The sections were then incubated at $4^{\circ} \mathrm{C}$ overnight with 1:100 dilutions of primary antibodies, ie, mouse anti-MMP-9 or anti-histone H2B (Santa Cruz Biotechnology). After washing thrice with PBS for 5 minutes, the slides were incubated with 1:250 dilutions of secondary antibodies conjugated to Alexa Fluor 488 (Molecular Probes, Eugene, OR) at room temperature for 1 hour. The slides were washed thrice with PBS, mounted in medium containing DAPI (Vector Laboratories, Burlingame, CA) and examined using an Eclipse E600 fluorescence microscope (Nikon, Tokyo, Japan).

\section{Isolation of Neutrophils from BALF and Blood}

Neutrophils from BALF of macrophage-depleted animals after influenza virus infection were isolated. ${ }^{44} \mathrm{On}$ $3 \mathrm{dpi}$, lungs were lavaged thrice with a total of $3 \mathrm{~mL}$ of PBS. The lavaged cells from three mice were pooled, washed once with PBS, filtered through a sterile MACS 30- $\mu \mathrm{m}$ pre-separation filter to remove cell clumps, and neutrophils were separated by negative selection using the MACS magnetic bead separation system (Miltenyi Biotec, Bergisch Gladbach, Germany) according to the manufacturer's instructions. The filtered cells were incubated with F4/80 and CD45R antibodies in PBS containing $1 \%$ BSA for 10 minutes on ice, followed by anti-IgG MicroBeads for 20 minutes on ice. The cells were then loaded onto MS columns connected to the MACS magnet. The eluted cells were tested for purity and viability by the trypan blue exclusion assay. For uninfected controls, neutrophils were isolated from whole blood using the dextran-Ficoll method.

\section{In Vitro Induction of NETS}

Enhanced attachment of neutrophils to infected epithelial cells has been documented. ${ }^{45}$ We investigated whether interaction of activated neutrophils isolated from influenza virus-infected animals could induce 
NETs. To address this, we studied co-incubations of neutrophils with normal or influenza virus-primed LA-4 mouse alveolar epithelial cells. LA-4 cells were infected with influenza virus at a multiplicity of infection of 20 for 5 hours, the cells were separated using enzyme-free cell dissociation buffer (Millipore, Billerica, MA), counted and cocultured with neutrophils (1:5 ratio) in eight-well Lab-Tek chamber slides (Nunc, Roskilde, Denmark) incubated at $37^{\circ} \mathrm{C}$ with $5 \% \mathrm{CO}_{2}$ for 150 minutes. Influenza virus was stained with rabbit polyclonal antibody, followed by anti-rabbit Alexa Fluor 546 (Molecular Probes) as described previously. ${ }^{23}$ NETs were detected by staining with anti-MPO, FITC-phalloidin (for F-actin), and DAPI to determine the MPO localization within NETs.

\section{Mechanism of NETs Induction: Role of Redox Enzymes, Including NADPH Oxidase, Superoxide Dismutase, and MPO}

To investigate the role of redox enzymes in NETs induction, we co-incubated neutrophils with influenza virus-primed epithelial cells in the presence of antibodies or inhibitors of specific enzymes including 10 $\mu \mathrm{g} / \mathrm{mL}$ anti-MPO, $20 \mu \mathrm{mol} / \mathrm{L}$ diphenyleneiodonium chloride (DPI, an inhibitor of NADPH oxidase), 2 $\mathrm{mmol} / \mathrm{L}$ diethyldithiocarbamate [DETC, an inhibitor of superoxide dismutase (SOD)], or in the presence of 2 $\mu \mathrm{mol} / \mathrm{L} \mathrm{H}_{2} \mathrm{O}_{2}$. PMA served as the positive control for NETs induction. To test whether influenza virus infection of alveolar epithelial cells could induce superoxide, we stained the infected and uninfected cells with the selective mitochondrial superoxide indicator, MitoSOX Red (Molecular Probes). At 5 hours postinfection, alveolar epithelial cells were washed twice with PBS, and then incubated with $5 \mu \mathrm{mol} / \mathrm{L}$ MitoSOX Red for $15 \mathrm{~min}$, and DAPI for $5 \mathrm{~min}$ to stain the nuclei. The number of cells positive for MitoSOX Red was counted under fluorescence microscopy.

\section{Endothelial Damage by Neutrophils}

To investigate the role of NETs in endothelial injury, human umbilical vein endothelial cells (HUVECs) and neutrophils were co-incubated in the presence or absence of $\mathrm{H}_{2} \mathrm{O}_{2}$. Neutrophils incubated in the presence of $\mathrm{H}_{2} \mathrm{O}_{2}$ lead to HUVECs that are highly positive for propidium iodide. Endothelial damage was also assessed by release of thrombomodulin using Western blot analysis of the culture supernatant collected after 2 hours of incubation.

\section{Bacterial Killing Activity}

Bactericidal activity of the neutrophils was ascertained by co-incubating neutrophils with S. pneumoniae, S. aureus, or Klebsiella pneumoniae. Neutrophils $\left(10^{5} / \mathrm{mL}\right)$ were preincubated for 15 minutes with $10 \mu \mathrm{g} / \mathrm{mL}$ dihydrocytochalasin $\mathrm{B}$ (dHCB) to block phagocytosis, followed by addition of bacteria $\left(10^{4} / \mathrm{mL}\right)$, and further incubation at $37^{\circ} \mathrm{C}$ for 1 hour. Bacterial killing was measured as a percentage of control bacteria (bacteria incubated without neutrophils). Sample aliquots were plated on Luria broth agar or sheep blood agar for the determination of colonyforming units.

\section{Statistical Analyses}

The data were expressed as means \pm SE. Statistical analyses were performed by analysis of variance or Student's $t$-test. Differences in animal weights were analyzed by the Mann-Whitney $U$-test. A value of $P<0.05$ was considered statistically significant.
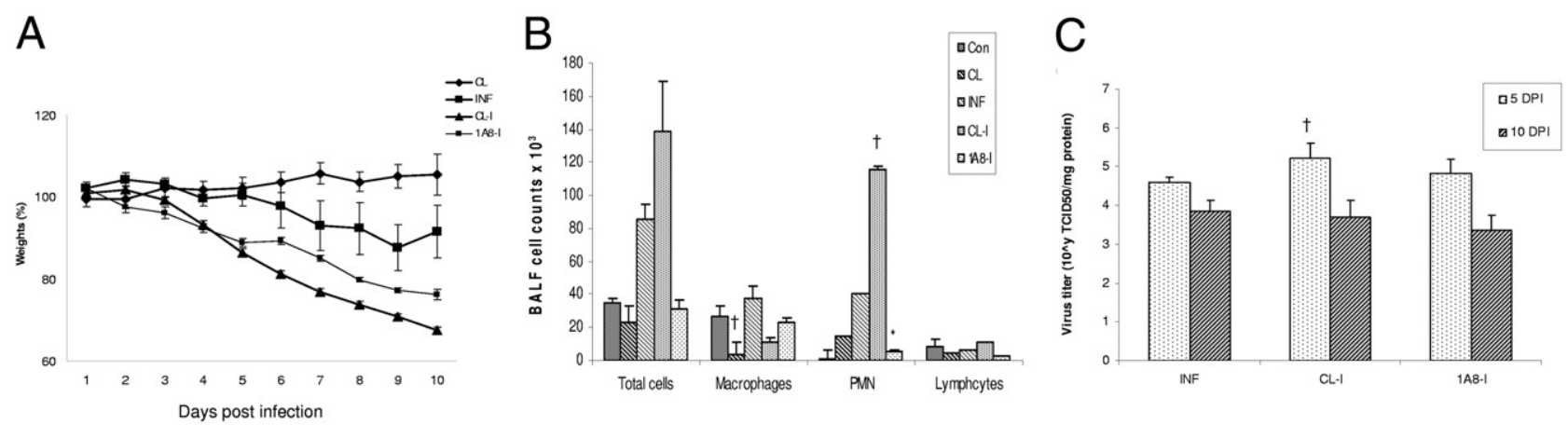

Figure 1. Effects of macrophage or neutrophil depletions on animal weight, leukocyte recruitment, and virus titer. Depletion of macrophages was achieved by intranasal administration of clodronate-liposome $(50 \mu \mathrm{L} /$ dose/mouse) at days -4 and -1 before virus challenge. For depletion of neutrophils or polymorphonuclear leukocytes (PMN), animals were injected intraperitoneally with anti-Ly $6 \mathrm{G}$ monoclonal antibody (1A8) at $200 \mu \mathrm{g} / \mathrm{dose} / \mathrm{mouse}$ a day before infection and every 48 hours thereafter. Animals were challenged with a sublethal dose of PR8 virus (100 PFU) through intranasal inoculation. A: Changes in body weight of BALB/c mice after infection. Animal weights were recorded daily for $10 \mathrm{dpi}$ and expressed as means \pm SE. At $10 \mathrm{dpi}$, the CL-I group showed more than $30 \%$ weight loss, whereas the $1 \mathrm{~A} 8$-I and INF groups displayed $20 \%$ and $10 \%$ weight loss, respectively $(n=10)$. B: Differential cell counts of BALF measured by modified Giemsa staining. Neutrophil-dominant infiltration was observed in the CL-I and INF groups. Macrophage numbers were significantly decreased in the CL-I group on 5 dpi. The 1A8-I group showed significantly decreased neutrophil numbers but increased macrophage numbers. Results are expressed as means \pm SE, with $n=5$ per group. C: Determination of virus titers in mouse lung homogenates at 5 and 10 dpi. MDCK cells were infected with serial 10 -fold dilutions of lung homogenates from uninfected or virus-infected animals. The numbers on the $y$ axis represent virus titers expressed as $10^{y} 50 \%$ tissue culture infectious dose $\left(\mathrm{TCID}_{50}\right)$ per gram of total protein (means $\pm \mathrm{SE}$ ), with $n=5$. CL, clodronate-liposome-treated; INF, infected; CL-I, clodronate-liposome-treated, infected; Con, normal allantoic fluid-inoculated; $1 \mathrm{~A} 8$-I: anti-Ly6G monoclonal antibody-treated, infected group. ${ }^{*} P<0.05$ versus the CL-I group; ${ }^{\dagger} P<0.05$ versus the INF and $1 \mathrm{~A} 8$-I groups 



Figure 2. Effects of macrophage or neutrophil depletion on histopathological changes and NETs induction in lungs of mice challenged with sublethal influenza virus infection. A: Animals administered clodronate-liposome displayed normal architecture of airway (BR) and alveolar epithelia (AV) with minimal neutrophilic infiltration. B: Infected mice showed mild peribronchial infiltration and damage of bronchiolar epithelium at 5 dpi. C and D: Macrophage-depleted infected mice at 5 dpi exhibited severe alveolar damage and extensive neutrophil infiltration (arrows). E and F: Neutrophil-depleted infected animals at 5 dpi displayed mild bronchiolitis and infiltration of macrophages in alveolar spaces (arrows), but neutrophils were rarely seen. G: Lungs from the INF group at 10 dpi exhibited mild alveolitis and bronchiolar epithelial regeneration with mild peribronchial inflammation. H: Neutrophil-depleted infected animals at 10 dpi revealed mild alveolar damage. I-K: Histopathological changes in lungs of mice from the CL-I group on $10 \mathrm{dpi}$. I: Lung sections show prominent pathological signs of diffuse alveolar damage with thickened interstitium, and alveolar spaces filled with protein exudates (asterisks). J: Extensive NETs formation at the terminal bronchioles opening into alveoli (white arrows). K: Bundles of NETs with endothelial damage (asterisk) were observed in large blood vessels. Magnifications: $\times 200$ (A, B, C, E, G $\mathbf{H}, \mathbf{I})$, and $\times 1000(\mathbf{D}, \mathbf{F}, \mathbf{J}, \mathbf{K})$. Scale bars: $50 \mu \mathrm{m}$. Semiquantitative histopathology scoring was performed $(n=5)$, with the scores shown in Table 1 .

\section{Results}

\section{Effects of Macrophage or Neutrophil Depletions on Clinical Signs, BALF Differential Cell Counts, and Virus Titers}

L-Cl2MDP treatment caused significant reduction of alveolar macrophages that was observed until day 8 postinoculation (data not shown). In infected mice, clinical signs, survival rates, and body weights were observed until $10 \mathrm{dpi}$. Macrophage-depleted, infected mice displayed signs of illness with ruffled fur, emaciation, inactivity, difficulty in breathing, and significant weight loss (Figure 1A), whereas neutrophil-depleted or nondepleted animals did not show respiratory distress. We observed a mortality of $40 \%$ in macrophage-depleted animals by 10 dpi, whereas none of the animals in the other infected groups died. Elevated numbers of total leukocytes including macrophages and neutrophils were noted following influenza virus infection (Figure 1B). As expected, macrophage-depleted animals showed decreased macrophages, but interestingly the total cell counts were higher than the other groups, with extensive neutrophil accumulation at $5 \mathrm{dpi}$. In comparison,
anti-Ly6G-treated and infected animals portrayed less neutrophil infiltration at $5 \mathrm{dpi}$. BALF total cell counts in all groups were significantly decreased by $10 \mathrm{dpi}$. Most strikingly, macrophage depletion enhanced viral replication, with higher peak viral titers at 5 dpi compared to neutrophil-depleted animals, thus indicating that macrophages are more critical in viral clearance from infected lungs. The virus titers declined by $10 \mathrm{dpi}$ in all groups (Figure 1C).

\section{Depletion of Macrophages Enhances Acute Lung Injury, Aggravates Pathological Changes and Hypoxemia}

Excessive accumulation of neutrophils and macrophages is a characteristic lesion found in highly pathogenic influenza virus infection of the lungs. Here, we evaluated histopathological changes in infected animals depleted of either macrophages or neutrophils to investigate the possible link of specific cellular infiltrations with ALI. Most notably, macrophage-depleted, infected mice displayed excessive recruitment of neutrophils on 5 dpi (Figure 2, C and D), and developed pathological complications of 
Table 1. Semiquantitative Scoring of Lung Histopathology

\begin{tabular}{ccccc}
\hline Sample & $\begin{array}{c}\text { Peribronchial inflammation/ } \\
\text { bronchiolitis }\end{array}$ & $\begin{array}{c}\text { Alveolar damage/ } \\
\text { interstitial inflammation }\end{array}$ & Hemorrhage & Edema \\
\hline $5 \mathrm{dpi}$ & & & 0 & 0 \\
CL & $0.2 \pm 0.1$ & $0.5 \pm 0.1$ & $0.3 \pm 0.2$ & $0.2 \pm 0.2$ \\
INF & $1.1 \pm 0.2$ & $1.1 \pm 0.3$ & $1.0 \pm 0.3$ & $0.7 \pm 0.2$ \\
CL-I & $2.4 \pm 0.3^{*}$ & $2.2 \pm 0.2^{*}$ & $0.5 \pm 0.1$ & $0.5 \pm 0.4$ \\
1A8-I & $0.6 \pm 0.1$ & $1.1 \pm 0.1$ & 0 & 0 \\
$10 \mathrm{dpi}$ & $0.4 \pm 0.2$ & $0.3 \pm 0.1$ & $1.0 \pm 0.3$ & $1.1 \pm 0.3$ \\
CL & $1.3 \pm 0.2$ & $1.5 \pm 0.2$ & $2.3 \pm 0.3^{*}$ & $2.9 \pm 0.3^{*}$ \\
INF & $1.9 \pm 0.2$ & $2.9 \pm 0.2^{*}$ & $1.3 \pm 0.2$ & $1.3 \pm 0.1$ \\
CL-I & $1.1 \pm 0.1$ & $1.7 \pm 0.1$ & &
\end{tabular}

${ }^{*} P<0.05$ versus other groups.

1A8-I: anti-Ly6G monoclonal antibody-treated, infected group; CL, clodronate-liposome-treated; CL-I, clodronate-liposome-treated, infected; dpi, days postinfection; INF, infected.

DAD with accumulation of edema fluid, protein exudates, erythrocytes within alveolar air spaces, and thickened interstitium by $10 \mathrm{dpi}$ (Figure 2I). In contrast, the neutrophil-depleted (Figure 2, E, F, and $\mathrm{H}$ ) and infected groups (Figure 2, B and $\mathrm{G}$ ) showed no signs of ARDS, although bronchitis and peribronchial inflammation were prominent at $5 \mathrm{dpi}$. Alveolitis with denuded epithelium and disintegrated interstitium were also more prominent in macrophage-depleted animals. Hemorrhage was rarely observed on day $5 \mathrm{dpi}$, whereas the presence of erythrocytes was more prominent on $7 \mathrm{dpi}$ in macrophagedepleted mice (data not shown). By $10 \mathrm{dpi}$, all macrophage-depleted animals showed severe hemorrhage with accumulation of erythrocytes within air spaces compared to their nondepleted counterparts. Interestingly, in both infected groups, the cellular infiltrations declined by 10 dpi despite their distinct pathological manifestations. Clodronate-treated, anti-Ly6G-treated, or uninfected control animals showed no apparent pathological changes, except that clodronate-treated uninfected mice displayed minimal neutrophil infiltration on $5 \mathrm{dpi}$ (Figure 2A) that resolved by $10 \mathrm{dpi}$. Table 1 summarizes the semiquantitative data of the histopathological analyses. In concurrence with the latter, blood gas analysis on 10 dpi revealed decreased partial pressure of arterial oxygen $\left(\mathrm{pAO}_{2}\right)$ and saturation of arterial oxygen $\left(\mathrm{sAO}_{2}\right)$ in macrophage-depleted animals compared to their infected neutrophil-depleted and nondepleted counterparts. On the other hand, increased partial pressure of arterial carbon dioxide $\left(\mathrm{pACO}_{2}\right)$ in macrophage-depleted animals suggested severe hypoxemia (Table 2). Secondary bacterial pneumonia following primary influenza virus infection constitutes an important complication and cause of death. To exclude the possibility that ALI and ARDS were due to secondary bacterial infections, we plated the BALF samples onto nutrient and blood agar. The resultant bacterial counts were very low (ranging from 0 to 275 colony-forming units $/ \mathrm{mL}$ ) for the control, infected, and macrophage-depleted groups, thus excluding secondary bacterial pneumonia associated with ALI or ARDS.

\section{NETs Formation, Acute Lung Injury, and Neutrophil Activation Are Prominent Features in Infected Macrophage-Depleted Animals}

Intriguingly, prominent NETs formation was noteworthy in the lung tissues of macrophage-depleted animals on $10 \mathrm{dpi}$ (Figure 2, I to K). NETs were observed individually attached to the alveolar epithelial lining within the areas of tissue damage. Owing to the processing and thin sectioning of fixed tissue, the DNA strands emanating from neutrophils frequently appeared as condensed small extensions originating from the cells. NETs formation was rarely observed in neutrophil-depleted or nondepleted infected animals on both 5 and 10 dpi.

Alveolar-capillary damage represents the most characteristic lesion in ALI. We examined the release of cellspecific injury markers in BALF samples. Levels of T1- $\alpha$ and thrombomodulin (alveolar type I and endothelium membrane proteins, respectively) were significantly elevated in infected macrophage-depleted animals compared with other infected groups. We also found increased neutrophil granule-specific proteins (including MMP-9) in macrophage-depleted mice compared to other groups (Figure 3). In concordance with severe pulmonary edema in the air spaces, we found substantially elevated protein levels in the BALF of macrophage-depleted animals compared to other groups (Figure 4A). The levels of proteins in neutrophil-depleted animals were higher than the infected nondepleted group, possibly due to damage of alveolar epithelium by virus infection. Furthermore, comparison of the activities of MPO in

Table 2. Arterial Blood Gas Analyses

\begin{tabular}{lcccl}
\hline & $\mathrm{pAO}_{2}(\mathrm{kPa})$ & $\mathrm{pACO}_{2}(\mathrm{kPa})$ & $\mathrm{pH}$ value & $\mathrm{sAO}_{2}(\%)$ \\
\hline $\mathrm{CL}$ & $11.2 \pm 0.3$ & $5.9 \pm 0.26$ & $7.2 \pm 0.1$ & $91 \pm 2.7$ \\
$\mathrm{INF}$ & $8.6 \pm 0.79$ & $6.2 \pm 0.21$ & $7.2 \pm 0.1$ & $77 \pm 5.1$ \\
$\mathrm{CL}-\mathrm{I}$ & $5.5 \pm 0.21^{\star}$ & $6.8 \pm 0.33$ & $7.3 \pm 0.2$ & $67 \pm 4.6^{*}$ \\
$1 \mathrm{~A} 8-\mathrm{I}$ & $8.0 \pm 0.9$ & $5.5 \pm 1.8$ & $7.2 \pm 0.1$ & $87 \pm 0.7$ \\
\hline
\end{tabular}

${ }^{*} P<0.05$ versus other groups.

$\mathrm{pAO}_{2}$, partial pressure of arterial oxygen; $\mathrm{sAO}_{2}$, saturation of arterial oxygen; CL, clodronate-liposome-treated; INF, infected; CL-I, clodronateliposome-treated, infected; 1A8-I: anti-Ly6G monoclonal antibodytreated, infected group. 

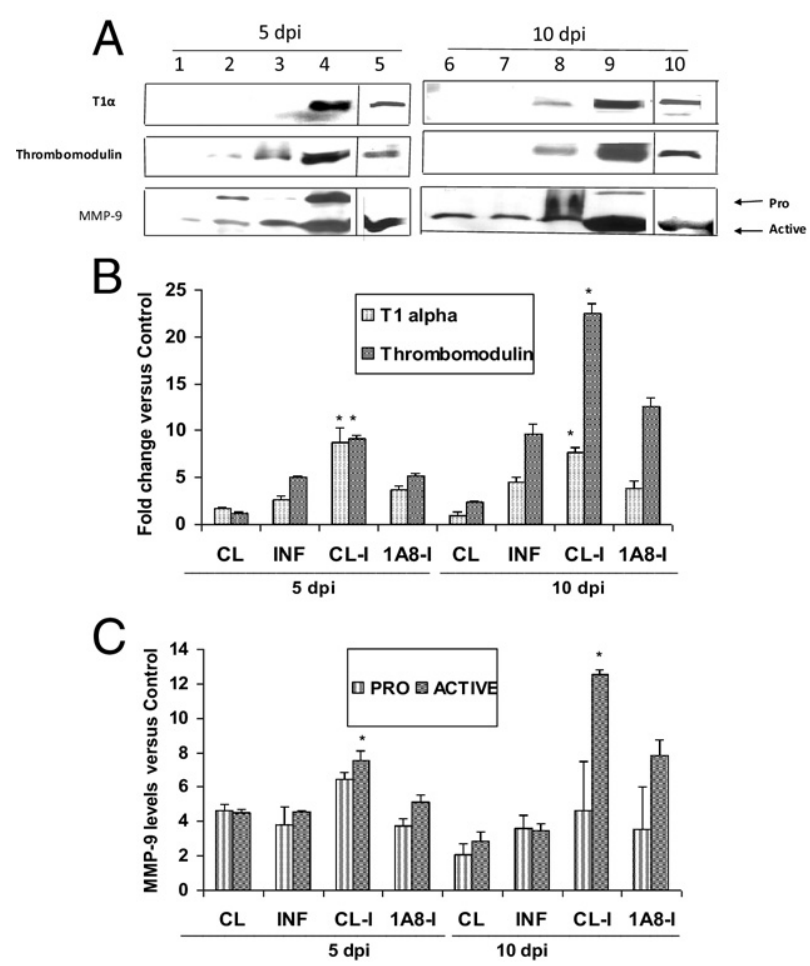

Figure 3. Assessment of acute lung injury by determining alveolar-capillary damage and release of MMP-9 into the alveolar air spaces. A: Damage of the thin microvascular barrier was determined using Western blot analyses of BALF samples for T1- $\alpha$ and thrombomodulin, which are membrane proteins present on alveola type I pneumocytes and capillary endothelium. Lanes depict BALF samples from five groups: uninfected control (lanes 1 and 6); CL (lanes $\mathbf{2}$ and 7); INF (lanes 3 and 8); CL-I (lanes 4 and 9); and 1A8-I (lanes 5 and 10). T1- $\alpha$ and thrombomodulin levels were significantly elevated in the BALF of the CL-I group at both 5 and $10 \mathrm{dpi}$ (lanes $\mathbf{4}$ and 9) compared to other groups. To determine the impact of neutrophil accumulation on lung injury, pro- and active MMP-9 levels were also assayed using Western blot analysis. Significantly increased MMP-9 levels were observed in CL-1 compared to other groups, thus alluding to the contribution of MMP-9 to basement membrane degradation and promoting tissue damage. $\mathbf{B}$ and $\mathbf{C}$ : Densitometric analyses of Western blot bands, each expressed as fold change versus the control group. Data are represented as means \pm SE, with $n=5$ per group. ${ }^{*} P<0.05$ versus other groups.

BALF and lung homogenates of macrophage-depleted versus other groups on $5 \mathrm{dpi}$ (Figure 4, B and C), implicate the role of neutrophils in the complication of ALI. By $10 \mathrm{dpi}$, overall MPO activities decreased in all groups, which was congruent with the reduced neutrophilic infiltration in the lungs on $10 \mathrm{dpi}$

\section{Lethal Challenge of Mice with Influenza Virus Induces NETs Formation within Lungs}

To substantiate that NETs induction is linked with severe lung injury not as a consequence of the absence of macrophages (since we observed extensive NETs in macrophage-depleted infected mice), we challenged normal mice with lethal doses of influenza virus. By day 6 , animals exhibited severe respiratory distress with extensive consolidation in lungs (Figure 5A), which showed NETs induction within these lesions. Extensive induction of NETS was found in infected lungs, predominantly within the alveoli, evident by histopathology and immunofluorescence analysis (Figure 5, A to E). NETs were largely lodged in areas of tissue consolidation, and DNA fibers were entangled with the alveolar epithelium and small blood vessels in areas with hemorrhagic lesions, indicating that NETs may contribute to thin alveolarcapillary damage. Occasionally, NETs appeared as extended nuclei attached to the endothelium of large blood vessels, or to the bronchiolar epithelial lining causing occlusions in small airways (Figure 5, C and E). Immunostaining revealed the presence of histone $\mathrm{H} 2 \mathrm{~B}$ and MMP-9 colocalized with DNA chromatin fibers (Figure 5, $F$ and $G$ ).

\section{In Vitro Studies on Induction of NETs and Their Role in Endothelial Injury}

Each BALF specimen was added to $3 \mathrm{~mL}$ of $\mathrm{F} 12 \mathrm{~K}$ medium containing $1 \%$ serum, and neutrophils were isolated by the magnetic separation system. The average yield from each mouse ranged from 1 to $3 \times 10^{5}$ cells, whereas cell viability was $>90 \%$. Flow cytometry and MPO immunostaining were performed as a purity check.

\section{MPO and Superoxide-Generated $\mathrm{H}_{2} \mathrm{O}_{2}$ Induce NETs Formation in Neutrophil-Epithelial Cocultures}

Neutrophils isolated from normal or influenza virusinfected mice form sporadic NETs when cocultured with normal LA-4 mouse alveolar epithelial cells (Figure 6E). However, a substantial increase in NETs formation was
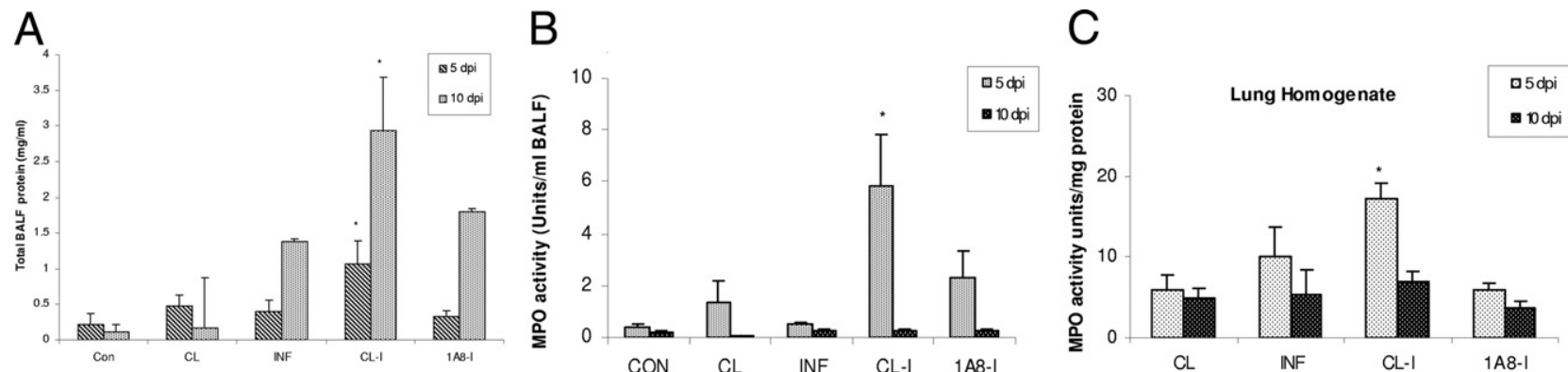

Figure 4. Effects of macrophage or neutrophil depletion on protein leakage into the air spaces and on MPO enzyme activity. A: Significant increase in BALF protein content was observed in the CL-I group compared to other groups, indicating alveolar capillary damage. B and C: MPO activities measured in both BALF samples and lung homogenates from the CL-I group were significantly increased compared to the other groups, correlating with intense neutrophil recruitment. Data are represented as means $\pm \mathrm{SE}$, with $n=5 .{ }^{*} P<0.05$ versus other groups 

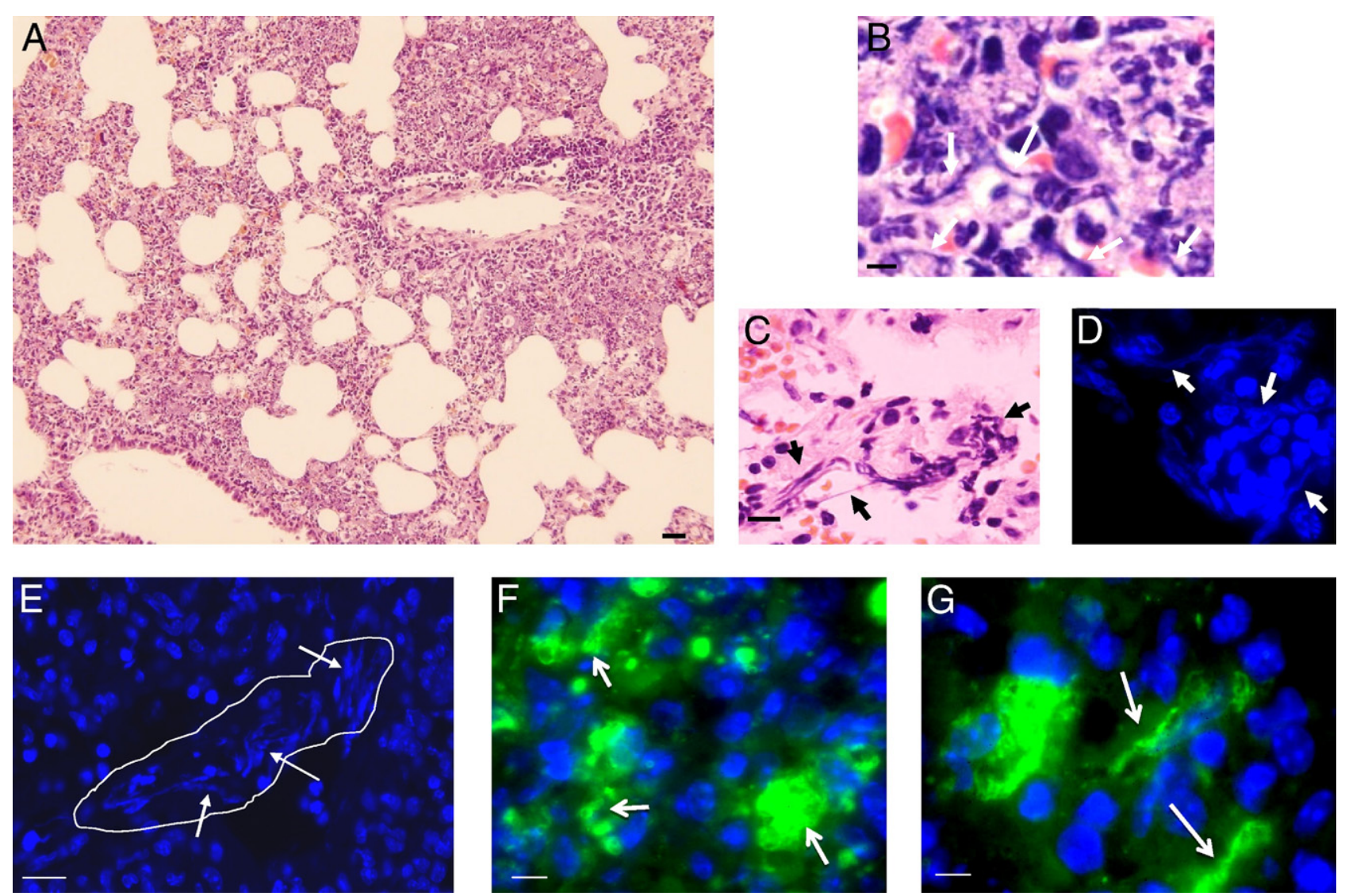

Figure 5. In vivo evidence for NETs formation after lethal challenge of influenza virus in mice. Paraffin-embedded lung tissues from mice challenged with lethal doses of influenza A/PR/8 H1N1 virus (500 PFU) were stained with hematoxylin-eosin or by immunofluorescence. A: Histopathology of lungs showing tissue consolidation and alveolar destruction. B: Extensive induction of NETs was detected within the alveoli (white arrows). C: Bundles of NETs were also observed in large blood vessels showing damaged endothelium (arrows). D and E: Nuclei stained with DAPI showing alveoli (white arrows) or occlusion in the bronchiole (defined by the white line). F and G: NETs were identified by close localization of DNA (blue) with histone H2B (F, green), and neutrophil granule marker MMP-9 (G, green). White arrows indicate NETs formation. Scale bars: $20 \mu \mathrm{m}(\mathbf{A}) ; 50 \mu \mathrm{m}(\mathbf{B}-\mathbf{G})$.

observed when neutrophils from infected mice were coincubated with alveolar epithelial cells primed with influenza virus (Figure 6, A to C). NETs induction was significantly reduced in the presence of anti-MPO antibody (Figure 6F). The formed NETs were entangled with infected epithelial cells (Figure 6C), suggesting that NETs induction may be an active process during the crosstalk between these cell types. Immunostaining of MPO (red), F-actin (green), and DNA (DAPI) revealed the presence of MPO on released NETS, with the actin remaining within their cell of origin (Figure 6D). Figure 6G depicts isolated neutrophils with intact nuclei.

Redox enzymes or cytokines such as IL-8 are known inducers of NETs. The potential link between NETs induction and degranulation has also been postulated. We observed increased mitochondrial superoxide levels in infected LA-4 epithelial cells in vitro as measured by the MitoSOX Red assay (infected cells $=48.1 \pm 7.4$, uninfected cells $=16.9 \pm 5.4, P<0.05)$. Influenza virus infection also enhanced levels of epithelial cell-derived neutrophil attractant-78 (ENA-78 or CXCL-5) in LA-4 cells (4.1-fold greater than the uninfected control, $P<0.05$ ). To understand the mechanism of NETs induction during epithelial-neutrophil interaction, the coculture was incubated in the presence of anti-MPO antibody, DPI (NADPH oxidase inhibitor), DETC (SOD inhibitor), or anti-ENA-78 antibody. As shown in Figure $6 \mathrm{H}$, significant reduction in NETs release was observed in the presence of anti-MPO and SOD inhibitor, but not with DPI or anti-ENA-78. The opposite effects of DETC and DPI on NETs formation may be attributed to the different modes of action of the inhibitors at the concentrations tested. The SOD-related conversion of superoxide to $\mathrm{H}_{2} \mathrm{O}_{2}$ is blocked by DETC, ${ }^{46}$ whereas DPI inhibits NADPH oxidase, nitric oxide synthase, and xanthine oxidase. ${ }^{47}$ Furthermore, exposure of $\mathrm{H}_{2} \mathrm{O}_{2}$ alone significantly induced NETs formation. These results suggest that superoxide-generated $\mathrm{H}_{2} \mathrm{O}_{2}$ may contribute to NETs induction in influenza pneumonia. These studies also indicate that NETs formation is an active mechanism which could participate in ALI. A possible hypothesis is that influenza virus infection of epithelial cells induces superoxide and $\mathrm{H}_{2} \mathrm{O}_{2}$ generation, which in turn stimulate MPO present on the surface of neutrophils, thus inducing NETs and mediating tissue injury.

\section{NETs Mediate Endothelial Cell Damage}

To ascertain whether NETs are involved in endothelial injury, HUVECs and neutrophils were co-incubated with or without $\mathrm{H}_{2} \mathrm{O}_{2} \cdot{ }^{48}$ Endothelial cell damage was signifi- 

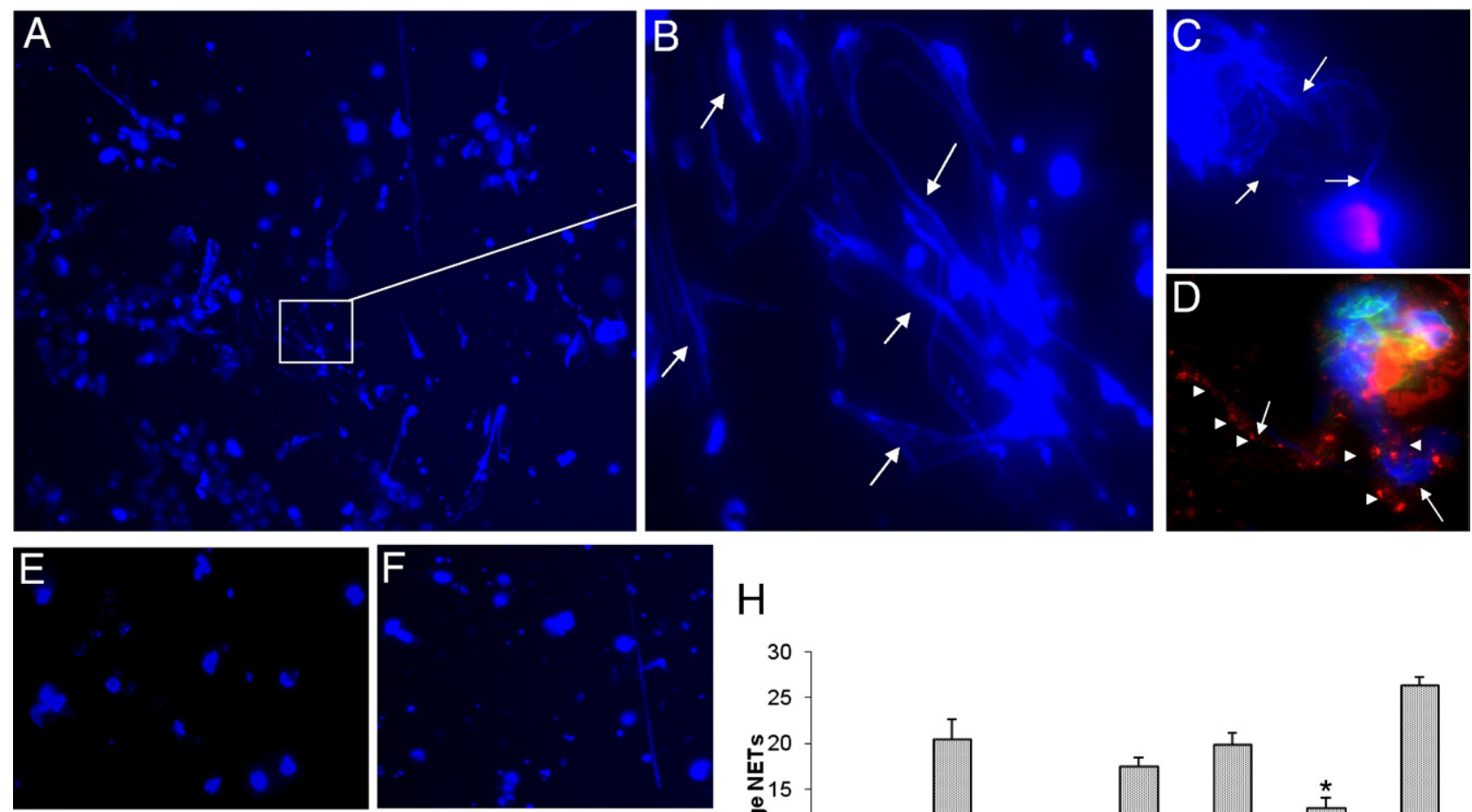

$\mathrm{H}$
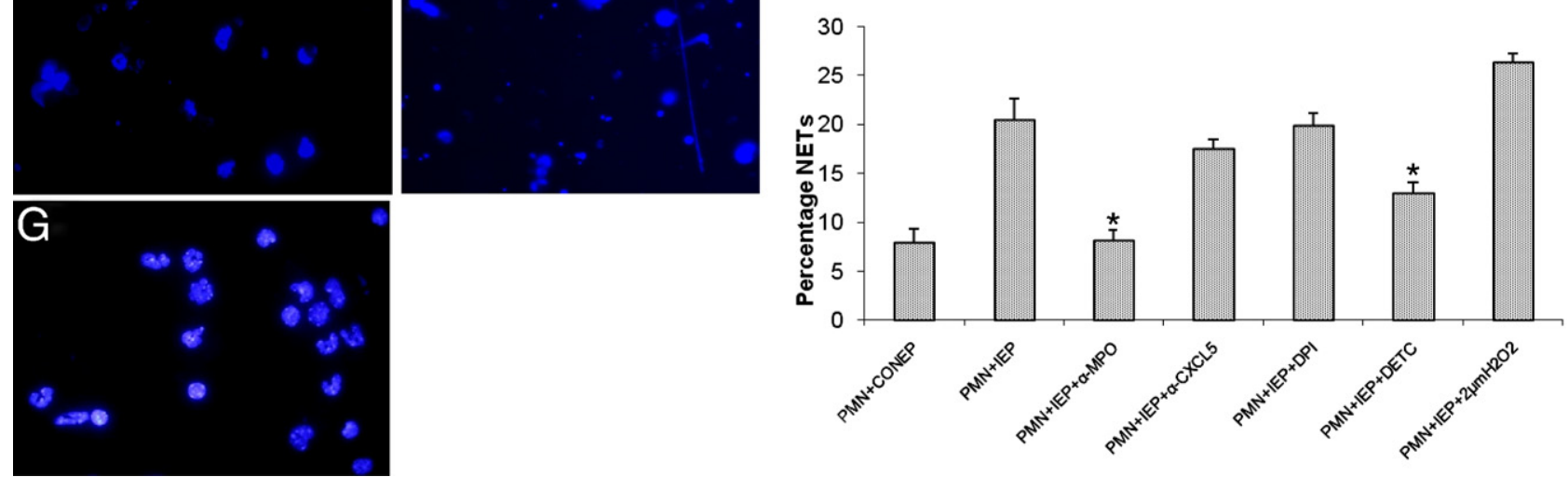

Figure 6. In vitro NETs induction by co-incubation of neutrophils with infected alveolar epithelial cells, and the role of redox enzymes. Neutrophils isolated from lungs were incubated with influenza virus-infected alveolar epithelial cells (at a multiplicity of infection of 20 for 5 hours) in the presence of inhibitors of specific enzymes, including $10 \mu \mathrm{g} / \mathrm{mL}$ anti-MPO, $20 \mu \mathrm{mol} / \mathrm{L}$ diphenyleneiodonium chloride (DPI, inhibitor of NADPH oxidase), $2 \mathrm{mmol} / \mathrm{L}$ diethyldithiocarbamate (DETC, inhibitor of SOD), or $2 \mu \mathrm{mol} / \mathrm{L} \mathrm{H}_{2} \mathrm{O}_{2}$. After 150 minutes of incubation, the DNA release was visualized by fluorescence microscopy with DAPI staining. A and B: Induction of NETs when neutrophils were co-incubated with infected alveolar epithelial cells (white arrows). C: Double staining with anti-influenza antibody showing infected epithelial cells embroiled by NETs (white arrows). Influenza virus was stained with anti-rabbit polyclonal antibody and secondary anti-rabbit Alexa Fluor 546 (orange). D: NETs stained with anti-MPO (arrowheads) FITC-phalloidin (for F-actin) and DAPI (arrow) to detect the MPO localization within NETs. E: Neutrophils co-incubated with uninfected alveolar epithelial cells revealed minimal NETs generation in the absence of viral stimulation. F: Neutrophils incubated in the presence of anti-MPO antibody resulted in decreased NETs induction. G: Neutrophils alone showing intact nuclei. H: Quantitative assessment of the percentage of NETs-forming cells revealed significant NETs induction following co-incubation of neutrophils (PMN) with infected alveolar epithelial cells (IEP), but not with uninfected control epithelial cells (CONEP). NETs induction was significantly diminished in the presence of anti-MPO and DETC, but not by DPI or anti-ENA-78 (anti-CXCL-5). The presence of $\mathrm{H}_{2} \mathrm{O}_{2}$ also significantly induced NETs formation. Values are means \pm SE of three independent experiments. ${ }^{*} P<0.05$ versus $\mathrm{PMN}+\mathrm{IEP}$ group.

cantly enhanced when the coculture was incubated in the presence of $\mathrm{H}_{2} \mathrm{O}_{2}$ as evident from increased percentages of cells positive for propidium iodide, as well as the release of thrombomodulin into the culture supernatant (Figure 7, A and B).

\section{NETs Do Not Universally Participate in Bacterial Killing in Vitro}

To determine whether NETs formation acts a defense strategy against secondary bacterial pneumonia during influenza virus infection, we incubated the neutrophils with $S$. pneumoniae, $S$. aureus, or $K$. pneumoniae in the presence of dHCB (an inhibitor of phagocytic activity). NETs inhibited the growth of $K$. pneumoniae to some extent, but not the other two bacteria (data not shown), suggesting that NETs may not be universally potent in clearing secondary bacterial infections.

\section{Discussion}

This study reveals three major findings. Firstly, mice challenged with sublethal doses of influenza virus after macrophage depletion exhibited aggravated pathological lesions that further developed into ARDS-like complications and hypoxemia. Histopathological and biochemical analyses showed excessive neutrophil infiltration, destruction of the microvascular bed, and pulmonary edema. In contrast, infected neutrophil-depleted and nondepleted animals exhibited mild lung injury. Second, our data provide the first evidence demonstrating NETs induction in influenza virus pneumonitis in vivo with their prominent appearance within alveoli and airways, and in lesions of tissue injury. Thirdly, co-incubation of neutrophils with influenza virus-primed alveolar epithelial cells induced release of NETs, which was abrogated by inhibitors of redox enzymes (including MPO and SOD), thus implicating redox enzymes in NETs formation. 


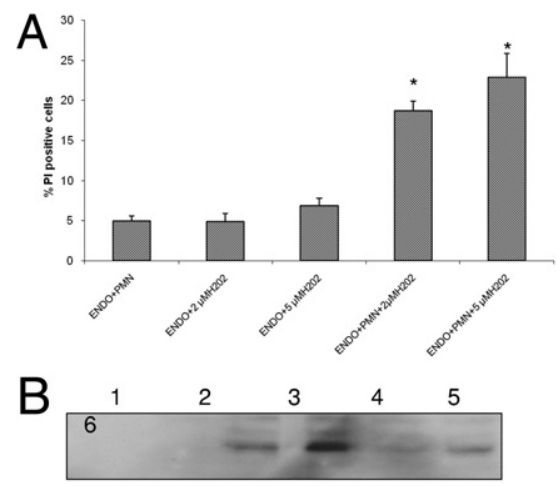

Figure 7. NETs-induced endothelial cell damage. Neutrophils (PMN) were incubated with HUVECs (ENDO) in the presence or absence of 2 or $5 \mu \mathrm{mol} / \mathrm{L}$ of $\mathrm{H}_{2} \mathrm{O}_{2}$. Endothelial damage was assessed by propidium iodide staining followed by immunofluorescence analysis. A: Neutrophils alone do not induce endothelial damage, but the presence of $\mathrm{H}_{2} \mathrm{O}_{2}$ significantly induced NETs to cause significant endothelial damage as indicated by increased propidium iodide-positive cells. Statistical significance at ${ }^{*} P<0.05$ versus other groups. B: Western blot analysis for release of thrombomodulin into the culture supernatant. Lanes 1 and 2: Supernatants from neutrophil-endothelium cocultures without $\mathrm{H}_{2} \mathrm{O}_{2}$ or in the presence of (lane 3) $2 \mu \mathrm{mol} / \mathrm{L}$ $\mathrm{H}_{2} \mathrm{O}_{2}$ or (lane 4) $5 \mu \mathrm{mol} / \mathrm{L} \mathrm{H}_{2} \mathrm{O}_{2}$. Supernatants of HUVECs alone in the presence of (lane 5) $2 \mu \mathrm{mol} / \mathrm{L} \mathrm{H}_{2} \mathrm{O}_{2}$ or (lane 6) $5 \mu \mathrm{mol} / \mathrm{L} \mathrm{H}_{2} \mathrm{O}_{2}$. The data are expressed as means $\pm \mathrm{SE}$ of three independent experiments.

Accumulating evidence underscores that most patients with severe influenza infections suffer from complications of ARDS, whereas histopathological analyses of their lungs reveal dominant neutrophilic accumulation in affected regions with tissue consolidation and DAD. ${ }^{17-20}$ Macrophages and neutrophils comprise the majority of cells that are recruited into infected lungs, and are linked with immunopathology. ${ }^{31}$ Our studies have revealed that mice depleted of macrophages and challenged with sublethal influenza developed severe clinical signs of ARDS and suffered from hypoxemia, with gross appearance of highly edematous and hemorrhagic lungs, whereas neutrophil depletion resulted only in mild lung injury. These results are congruent with previous studies demonstrating relatively high mortalities in macrophage-depleted mice compared to neutrophil-depleted mice challenged with 1918 reconstituted virus. ${ }^{21}$ Furthermore, our studies revealed that macrophage depletion led to intense neutrophilic infiltration into alveoli and airways as observed at $5 \mathrm{dpi}$, and eventually these mice portrayed clinical signs of ARDS and histological features of DAD, with alveolar spaces filled with proteinaceous exudates and erythrocytes by $10 \mathrm{dpi}$. Severe hypoxemia in macrophagedepleted infected animals was evident by decreased $\mathrm{pAO}_{2}$ and $\mathrm{sAO}_{2}$ levels, compared to their nondepleted or neutrophil-depleted counterparts. Neutrophil-depleted or nondepleted infected mice had milder lung injury with more prominent bronchopneumonia. Progressive pathological complications of ALI were observed in macrophage-depleted animals at 7 and 8 dpi (data not shown) with prominent clinical signs of respiratory distress. A previous study showed that neutrophil depletion was associated with increased lethality in H3N2 infection, with mainly bronchitis and systemic viral spread. ${ }^{28}$ In contrast, our mouse model displayed severe alveolitis and pulmonary edema. Compared to nondepleted or neutrophil-depleted mice, high viral titers were observed in macrophage-depleted mice despite the intense influx of neutrophils, implying that macrophages are more important in viral clearance. These findings concur with previous studies on influenza infections in pigs and mice. No significant bacterial infection was noticed in any group, suggesting that damage was not attributable to secondary bacterial pneumonia.

Neutrophils are implicated in ALI caused by various stimuli, and intriguing evidence exists to support their association with complications of ALI and ARDS in influenza pathogenesis. ${ }^{8,9}$ To corroborate the histopathological evidence, we observed increased protein leakage, and MPO and MMP-9 activities in the lung lavage of macrophage-depleted compared to nondepleted or neutrophil-depleted infected mice. Moreover, elevated levels of T1- $\alpha$ and thrombomodulin (membrane proteins of alveolar type I pneumocytes and endothelium, respectively) in BALF of infected macrophage-depleted animals reflected damage of the pulmonary microvascular bed. Alveolar type I cells and endothelium constitute the microvascular bed that forms the physical barrier that prevents fluid flux into the air spaces. Previously, we demonstrated enhanced apoptotic death of infected alveolar epithelial cells during blockade of macrophage recruitment into the lungs. ${ }^{43}$ Our results indicate that excessive neutrophil recruitment, activation, and release of toxic enzymes can exacerbate the damage of alveolar epithelium by virus infection, leading to vascular leakage, pulmonary edema, and hypoxemia, thus finally developing into ARDS.

Several groups have demonstrated that NETs formation is a novel strategy by neutrophils for trapping bacteria with their web-like structures consisting of proteoIytic and chromatin material. NETs formation is also linked with tissue injury in sepsis and small vessel vasculitis. ${ }^{30,35}$ The DNA entangled with the endothelium of small blood vessels appear with capillary damage both in vivo and in vitro. ${ }^{35}$ Here, we provide novel data to validate the induction of NETs following lethal influenza virus challenge of mice. Bundles of DNA fibers appeared prominently in the alveoli and terminal bronchioles within areas of tissue consolidation. Only a subpopulation of neutrophils produced NETs, since we also detected unstimulated neutrophils with disintegrated nuclei that were undergoing apoptosis or necrosis. The existence of DNA fibers closely entangled to the alveolar epithelium suggests that these structures may contribute to damage of the alveolar-capillary barrier. Occasionally, NETs were found attached to the endothelium of large blood vessels or occluding some of the airways. Similar observations were made in small vessel vasculitis and sepsis, wherein extensive NETs accumulate inside the glomerular capsule or cause occlusion of sinusoids, and NETs were prominent in patient tissue biopsies with intense neutrophil infiltration. Immunostaining revealed the presence of histone, MMP-9, and MPO colocalized with DNA chromatin fibers. NETs formation in macrophage-depleted infected mice was more obvious, thus suggesting that NETs induction may participate in pathological events, and spur progression toward ARDS. In contrast, lungs of 
nondepleted or neutrophil-depleted infected animals only showed scattered NETs formation.

Due to the close proximity of NETS with the alveolarcapillary surface, we next asked whether the crosstalk between neutrophils and infected alveolar epithelial cells could instigate NETs formation. Neutrophils isolated from influenza virus-infected mice indeed stimulated NETs release when incubated with murine alveolar epithelial cells primed with influenza virus, thus suggesting that interactions of these cells are critical for NETs generation. NETs formation is a distinct mode of cell death induced by reactive oxygen intermediates, NADPH oxidase, and cytokines such as IL-8. ${ }^{37,49}$ Influenza virus infection of alveolar epithelial cells led to increased superoxide activity and elevated CXCL-5, a chemokine known to stimulate neutrophils and induce chemotaxis. To investigate the mechanism of NETs, we used inhibitors or antibodies against CXCL-5 and redox enzymes (including MPO, SOD, NADPH oxidase). We found that inhibition of MPO and SOD, but not of NADPH oxidase, reduced NETs generation. Concurrently, we observed extensive NETs induction when neutrophils were incubated in the presence of $\mathrm{H}_{2} \mathrm{O}_{2}$, a product of $\mathrm{SOD}$ activity. This finding was observed previously, ie, $\mathrm{H}_{2} \mathrm{O}_{2}$-generating enzyme can cause significant NETs induction. ${ }^{36}$ Taken together, these experiments describe a novel mechanism of NETs induction via $\mathrm{H}_{2} \mathrm{O}_{2}$ production by infected target cells. The generation of $\mathrm{H}_{2} \mathrm{O}_{2}$ may in turn activate MPO present on the neutrophil surface, and further investigations are warranted to understand how these interactions culminate in NETs induction.

Although NETs generation is documented in various infections, the role of NETs in viral infections is largely unknown. Although NETs were first identified to participate in bacterial killing, certain bacteria possess a defense strategy by producing endonucleases that can degrade the NETs. ${ }^{36,38}$ To test the functional significance of NETs in influenza, we performed endothelial injury and bactericidal activity studies. We found that NETs mediated damage of endothelial cells as evident by the cell death assay as well as by thrombomodulin release into the culture supernatant. Furthermore, incubation of neutrophils with different bacteria demonstrated that NETs inhibited the growth of $K$. pneumoniae to a certain degree, but not of $S$. pneumoniae or $S$. aureus when incubated with an inhibitor of phagocytic activity. These results suggest that NETs induced during influenza virus infection can contribute to lung injury, but have limited bactericidal activity.

Taken together, these studies indicate that complications of ARDS in influenza pneumonia culminate from heterogeneous events induced by influenza virusmediated cytopathic effects on the alveolar epithelium combined with neutrophil-stimulated aggravation of tissue injury via production of toxic enzymes and NETs generation that damage the microvascular bed. Furthermore, we document that NETs formation is an active process stimulated by redox enzymes. Hence, intervention strategies to inhibit neutrophil-mediated toxic enzymes or other degradative molecules will likely have potential therapeutic impact to ameliorate the severity of influenza pneumonia.

\section{Acknowledgments}

We thank Yaw-Chyn Lim for providing HUVECs, Meng Kwoon Sim for useful discussions, and Kelly Lau for technical assistance.

\section{References}

1. Beigel JH, Farrar J, Han AM, Hayden FG, Hyer R, de Jong MD Lochindarat S, Nguyen TK, Nguyen TH, Tran TH, Nicoll A, Touch S, Yuen KY; Writing Committee of the World Health Organization (WHO) Consultation on Human Influenza A/H5: Avian influenza A (H5N1) infection in humans. N Engl J Med 2005, 353:1374-1385

2. Bauer TT, Ewig S, Rodloff AC, Müller EE: Acute respiratory distress syndrome and pneumonia: a comprehensive review of clinical data. Clin Infect Dis 2006, 43:748-756

3. Yu H, Gao Z, Feng Z, Shu Y, Xiang N, Zhou L, Huai Y, Feng L, Peng Z, Li Z, Xu C, Li J, Hu C, Li Q, Xu X, Liu X, Liu Z, Xu L, Chen Y, Luo H, Wei L, Zhang X, Xin J, Guo J, Wang Q, Yuan Z, Zhou L, Zhang K, Zhang W, Yang J, Zhong X, Xia S, Li L, Cheng J, Ma E, He P, Lee SS, Wang Y, Uyeki TM, Yang W: Clinical characteristics of 26 human cases of highly pathogenic avian influenza A (H5N1) virus infection in China. PLoS One 2008, 3:e2985

4. Kawachi S, Luong ST, Shigematsu M, Furuya $H$, Phung TT, Phan PH, Nunoi H, Nguyen LT, Suzuki K: Risk parameters of fulminant acute respiratory distress syndrome and avian influenza (H5N1) infection in Vietnamese children. J Infect Dis 2009, 200:510-515

5. Miller RR, Markewitz BA, Rolfs RT, Brown SM, Dascomb KK, Grissom CK, Friedrichs MD, Mayer J, Hirshberg EL, Conklin J, Paine R, Dean NC: Clinical findings and demographic factors associated with ICU admission in Utah due to novel 2009 influenza $A(H 1 N 1)$ infection. Chest 2010, 137:752-758

6. Lew TW, Kwek TK, Tai D, Earnest A, Loo S, Singh K, Kwan KM, Chan Y, Yim CF, Bek SL, Kor AC, Yap WS, Chelliah YR, Lai YC, Goh SK: Acute respiratory distress syndrome in critically ill patients with severe acute respiratory syndrome. JAMA 2003, 290:374-380

7. Kobasa D, Jones SM, Shinya K, Kash JC, Copps J, Ebihara H, Hatta Y, Kim JH, Halfmann P, Hatta M, Feldmann F, Alimonti JB, Fernando L, Li Y, Katze MG, Feldmann H, Kawaoka Y: Aberrant innate immune response in lethal infection of macaques with the 1918 influenza virus. Nature 2007, 445:319-323

8. Xu T, Qiao J, Zhao L, Wang G, He G, Li K, Tian Y, Gao M, Wang J, Wang $\mathrm{H}$, Dong $\mathrm{C}$ : Acute respiratory distress syndrome induced by avian influenza $\mathrm{A}(\mathrm{H} 5 \mathrm{~N} 1)$ virus in mice. Am J Respir Crit Care Med 2006, 174:1011-1017

9. Deng G, Bi J, Kong F, Li X, Xu Q, Dong J, Zhang M, Zhao L, Luan Z, Lv N, Qiao J: Acute respiratory distress syndrome induced by H9N2 virus in mice. Arch Virol 2010, 155:187-195

10. Brown KA, Brain SD, Pearson JD, Edgeworth JD, Lewis SM, Treacher DF: Neutrophils in development of multiple organ failure in sepsis. Lancet 2006, 368:157-169

11. Kolls JK: Oxidative stress in sepsis: a redox redux. J Clin Invest 2006 , 116:860-863

12. Kodama T, Yukioka H, Kato T, Kato N, Hato F, Kitagawa S: Neutrophil elastase as a predicting factor for development of acute lung injury. Intern Med 2007, 46:699-704

13. Zmijewski JW, Lorne E, Zhao X, Tsuruta Y, Sha Y, Liu G, Siegal GP, Abraham E: Mitochondrial respiratory complex I regulates neutrophil activation and severity of lung injury. Am J Respir Crit Care Med 2008, 178:168-179

14. Zhao X, Zmijewski JW, Lorne E, Liu G, Park YJ, Tsuruta Y, Abraham $\mathrm{E}$ : Activation of AMPK attenuates neutrophil proinflammatory activity and decreases the severity of acute lung injury. Am J Physiol Lung Cell Mol Physiol 2008, 295:L497-L504

15. El Kebir D, Jozsef L, Pan W, Wang L, Petasis NA, Serhan CN, Filep JG: 15-epi-lipoxin A4 inhibits myeloperoxidase signaling and enhances resolution of acute lung injury. Am J Respir Crit Care Med 2009, 180:311-319 
16. Bdeir K, Higazi AA, Kulikovskaya I, Christofidou-Solomidou M, Vinogradov SA, Allen TC, Idell S, Linzmeier R, Ganz T, Cines DB: Neutrophil alpha-defensins cause lung injury by disrupting the capillaryepithelial barrier. Am J Respir Crit Care Med 2010, 181:935-946

17. Perez-Padilla R, de la Rosa-Zamboni D, Ponce de Leon S, Hernandez M, Quiñones-Falconi F, Bautista E, Ramirez-Venegas A, Rojas-Serrano J, Ormsby CE, Corrales A, Higuera A, Mondragon E, CordovaVillalobos JA; INER Working Group on Influenza: Pneumonia and respiratory failure from swine-origin influenza $A(\mathrm{H} 1 \mathrm{~N} 1)$ in Mexico. N Engl J Med 2009, 361:680-689

18. Mauad T, Hajjar LA, Callegari GD, da Silva LF, Schout D, Galas FR, Alves VA, Malheiros DM, Auler JO, Ferreira AF, Borsato MR, Bezerra SM, Gutierrez PS, Caldini ET, Pasqualucci CA, Dolhnikoff M, Saldiva $\mathrm{PH}$ : Lung pathology in fatal novel human influenza $\mathrm{A}(\mathrm{H} 1 \mathrm{~N} 1)$ infection. Am J Respir Crit Care Med 2010, 181:72-79

19. Djibre M, Berkane N, Salengro A, Ferrand E, Denis M, Chalumeau Lemoine L, Parrot A, Mayaud C, Fartoukh M: Non-invasive management of acute respiratory distress syndrome related to Influenza $A$ (H1N1) virus pneumonia in a pregnant woman. Intensive Care Med 2010, 36:373-374

20. Yokoyama T, Tsushima K, Ushiki A, Kobayashi N, Urushihata K, Koizumi T, Kubo K: Acute lung injury with alveolar hemorrhage due to a novel swine-origin influenza A (H1N1) virus. Intern Med 2010, 49:427-430

21. Kobasa D, Takada A, Shinya K, Hatta M, Halfmann P, Theriault S, Suzuki H, Nishimura H, Mitamura K, Sugaya N, Usui T, Murata T, Maeda Y, Watanabe S, Suresh M, Suzuki T, Suzuki Y, Feldmann H, Kawaoka Y: Enhanced virulence of influenza A viruses with the haemagglutinin of the 1918 pandemic virus. Nature 2004, 431:703-707

22. Tumpey TM, Basler CF, Aguilar PV, Zeng H, Solorzano A, Swayne DE Cox NJ, Katz JM, Taubenberger JK, Palese P, Garcia-Sastre A: Characterization of the reconstructed 1918 Spanish influenza pandemic virus. Science 2005, 310:77-80

23. Narasaraju T, Sim MK, Ng HH, Phoon MC, Shanker N, Lal SK, Chow VT: Adaptation of human influenza H3N2 virus in a mouse pneumonitis model: insights into viral virulence, tissue tropism and host pathogenesis. Microbes Infect 2009, 11:2-11

24. Sakai S, Kawamata H, Mantani N, Kogure T, Shimada Y, Terasawa K, Sakai $\mathrm{T}$, Imanishi N, Ochiai $\mathrm{H}$ : Therapeutic effect of anti-macrophage inflammatory protein 2 antibody on influenza virus-induced pneumonia in mice. J Virol 2000, 74:2472-2476

25. Crowe CR, Chen K, Pociask DA, Alcorn JF, Krivich C, Enelow RI, Ross TM, Witztum JL, Kolls JK: Critical role of IL-17RA in immunopathology of influenza infection. J Immunol 2009, 183:5301-5310

26. Perrone LA, Szretter KJ, Katz JM, Mizgerd JP, Tumpey TM: Mice lacking both TNF and IL-1 receptors exhibit reduced lung inflammation and delay in onset of death following infection with a highly virulent H5N1 virus. J Infect Dis 2010, 202:1161-1170

27. Tate MD, Brooks AG, Reading PC: The role of neutrophils in the upper and lower respiratory tract during influenza virus infection of mice. Respir Res 2008, 9:57

28. Tate MD, Deng YM, Jones JE, Anderson GP, Brooks AG, Reading PC: Neutrophils ameliorate lung injury and the development of severe disease during influenza infection. J Immunol 2009, 183:7441-7450

29. Brinkmann V, Reichard U, Goosmann C, Fauler B, Uhlemann Y, Weiss DS, Weinrauch Y, Zychlinsky A: Neutrophil extracellular traps kill bacteria. Science 2004, 303:1532-1535

30. Clark SR, Ma AC, Tavener SA, McDonald B, Goodarzi Z, Kelly MM, Patel KD, Chakrabarti S, McAvoy E, Sinclair GD, Keys EM, AllenVercoe E, Devinney R, Doig CJ, Green FH, Kubes P: Platelet TLR4 activates neutrophil extracellular traps to ensnare bacteria in septic blood. Nat Med 2007, 13:463-469

31. Perrone LA, Plowden JK, García-Sastre A, Katz JM, Tumpey TM: H5N1 and 1918 pandemic influenza virus infection results in early and excessive infiltration of macrophages and neutrophils in the lungs of mice. PLoS Pathog 2008, 4:e1000115

32. Curran CS, Demick KP, Mansfield JM: Lactoferrin activates macrophages via TLR4-dependent and -independent signalling pathways. Cell Immunol 2006, 242:23-30

33. Jaillon S, Peri G, Delneste Y, Frémaux I, Doni A, Moalli F, Garlanda C, Romani L, Gascan H, Bellocchio S, Bozza S, Cassatella MA, Jeannin $P$, Mantovani A: The humoral pattern recognition receptor PTX3 is stored in neutrophil granules and localizes in extracellular traps. J Exp Med 2007, 204:793-804

34. Wartha F, Beiter K, Normark S, Henriques-Normark B: Neutrophil extracellular traps: casting the NET over pathogenesis. Curr Opin Microbiol 2007, 10:52-56

35. Kessenbrock K, Krumbholz M, Schönermarck U, Back W, Gross WL, Werb Z, Grone HJ, Brinkmann V, Jenne DE: Netting neutrophils in autoimmune small-vessel vasculitis. Nat Med 2009, 15:623-625

36. Fuchs TA, Abed U, Goosmann C, Hurwitz R, Schulze I, Wahn V, Weinrauch Y, Brinkmann V, Zychlinsky A: A novel cell death program leads to neutrophil extracellular traps. J Cell Biol 2007, 176:231-241

37. Ermert D, Urban CF, Laube B, Goosmann C, Zychlinsky A, Brinkmann V: Mouse neutrophil extracellular traps in microbial infections. J Innate Immun 2009, 1:181-193

38. Beiter K, Wartha F, Albiger B, Normark S, Zychlinsky A, HenriquesNormark B: An endonuclease allows Streptococcus pneumoniae to escape from neutrophil extracellular traps. Curr Biol 2006, 16:401407

39. Wardini AB, Guimarães-Costa $A B$, Nascimento MT, Nadaes NR, Danelli MD, Mazur C, Benjamim CF, Saraiva EM, Pinto-da-Silva LH: Characterization of neutrophil extracellular traps in cats naturallyinfected with feline leukemia virus. J Gen Virol 2010, 91:259-264

40. Van Rooijen N, Sanders A, van den Berg TK: Apoptosis of macrophages induced by liposome-mediated intracellular delivery of clodronate and propamidine. J Immunol Methods 1996, 193:93-99

41. Van Rooijen NV, Sanders A: Liposome mediated depletion of macrophages: mechanism of action, preparation of liposomes and applications. J Immunol Methods 1994, 174:83-93

42. Daley JM, Thomay AA, Connolly MD, Reichner JS, Albina JE: Use of Ly6G-specific monoclonal antibody to deplete neutrophils in mice. J Leukoc Biol 2008, 83:64-70

43. Narasaraju T, Ng HH, Phoon MC, Chow VT: MCP-1 antibody treatment enhances damage and impedes repair of the alveolar epithelium in influenza pneumonitis. Am J Respir Cell Mol Biol 2010, 42: 732-743

44. Ferretti S, Bonneau O, Dubois GR, Jones CE, Trifilieff A: IL-17, produced by lymphocytes and neutrophils, is necessary for lipopolysaccharide-induced airway neutrophilia: iL-15 as a possible trigger. J Immunol 2003, 170:2106-2112

45. Wang SZ, Forsyth KD: The interaction of neutrophils with respiratory epithelial cells in viral infection. Respirology 2000, 5:1-10

46. Mugge A, Elwell JH, Peterson TE, Harrison DG: Release of intact endothelium-derived relaxing factor depends on endothelial superoxide dismutase activity. Am J Physiol 1991, 260:C219-C225

47. Wind S, Beuerlein K, Eucker T, Muller H, Scheurer P, Armitage ME, Ho $\mathrm{H}$, Schmidt HHHW, Wingler K: Comparative pharmacology of chemically distinct NADPH oxidase inhibitors. Br J Pharmacol 2010, 161: 885-898

48. Gotte M, Bernfield M, Joussen AM: Increased leukocyte-endothelial interactions in syndecan-1-deficient mice involve heparan sulfatedependent and -independent steps. Curr Eye Res 2005, 30:417-422

49. Knobil K, Choi AM, Weigand GW, Jacoby DB: Role of oxidants in influenza virus-induced gene expression. Am J Physiol 1998, 274: L134-L142 